\title{
Competitive Effects of Some Cations on Active Potassium Transport in the Human Red Blood Cell *
}

\author{
JOHN R. SACHS \\ (From the Department of Medicine, University of North Carolina School of Medicine, \\ Chapel Hill, North Carolina)
}

\begin{abstract}
The effect of some cations on the active potassium transport system of the human red blood cell has been investigated. At low extracellular potassium concentrations, extracellular sodium competitively inhibits the active potassium influx at all sodium concentrations investigated, and tetraethylammonium behaves in a fashion similar to that of sodium. At low extracellular concentrations of potassium, ammonium at low concentrations at first stimulates the active potassium influx, but at higher concentrations inhibits it. Tetramethylammonium at most slightly stimulates the active potassium influx, and calcium is without effect. The behavior is consistent with a model in which potassium is required at more than one site before transport occurs, and the sites are indistinguishable as far as their behavior toward the ions investigated is concerned. The affinity of the alkali metal cations for the sites appears to be explicable in terms of their physical characteristics.
\end{abstract}

\section{Introduction}

The relation between the active potassium influx in the human red blood cell and the extracellular potassium concentration cannot be described by a model of the Michaelis-Menten type in which a single potassium ion interacts with a saturable component of the membrane surface before transport occurs. Neither can the relation between the active sodium outflux and the extracellular potassium concentration be explained by this type model. A different kind of model has been described from which equations may be derived which describe the kinetics of the process (1). The model postulates that potassium ions

* Submitted for publication 9 February 1967; accepted 25 May 1967.

This work was supported by U. S. Public Health Service research grant $5 \mathrm{RO} 1 \mathrm{HE} 01301$ and training grant AM 05054.

$\ddagger$ Work done during the term of U. S. Public Health Service postdoctoral fellowship 5F2-AM-19,537.

Address requests for reprints to Dr. John R. Sachs, Department of Hematology, Division of Medicine, Walter Reed Army Institute of Research, Washington, D. C 20007. are required simultaneously at two saturable sites in the active transport mechanism before transport occurs. The behavior of the system in the presence of rubidium, cesium, and lithium is also consistent with a two site hypothesis. All three cations appear capable of substituting for potassium at either of the sites and consequently stimulate potassium influx when both potassium and either rubidium, cesium, or lithium are present at low concentrations, the ion other than potassium substituting at one of the potassium sites. At higher concentrations of rubidium, cesium, or lithium, the substitute ion replaces potassium at both sites and active potassium influx is inhibited. It is not possible to determine from this behavior whether these two hypothetical potassium sites are identical in their characteristics or whether they serve different functions in the transport system.

It seemed of interest to examine the influence of other cations on the potassium transport system in order to attempt to correlate the order of affinity of the potassium-sensitive sites for the ions with estimates of the hydrated ionic radii of the ions. 
It also seemed possible that, if the potassiumsensitive sites are not equivalent, an inhibitor might be found which would compete with potassium at one of the potassium-sensitive sites but not both. The cations investigated were sodium, calcium, ammonium, tetramethylammonium and tetraethylammonium.

We have found that sodium competitively inhibits potassium influx even at low concentrations of sodium and potassium, and that no concentration of extracellular sodium will stimulate potassium influx. Ammonium behaves in a manner similar to that of rubidium, cesium, and lithium, and the behavior of tetraethylammonium is similar to that of sodium. Tetramethylammonium and calcium have no marked effect on active potassium influx, even at very high concentrations.

\section{Methods}

The methods and calculations employed were identical to those previously described. Total potassium influx $\left({ }^{1} \mathrm{M}_{\mathrm{K}}{ }^{\mathrm{T}}\right.$ ) was measured in cells which had been depleted of ATP by an $18 \mathrm{hr}$ incubation at $37^{\circ} \mathrm{C}$ in the absence of glucose, and then incubated for $2 \mathrm{hr}$ in the presence of $500 \mathrm{mg}$ of glucose per $100 \mathrm{ml}, 3 \mathrm{~mm}$ adenine, and $10 \mathrm{~mm}$ inosine (to restore ATP levels) immediately before measurements were made. The passive potassium influx $\left({ }^{1} \mathrm{M}_{\mathrm{K}}{ }^{\mathrm{L}}\right)$ was measured in cells which were depleted of ATP by a $20 \mathrm{hr}$ incubation at $37^{\circ} \mathrm{C}$ in the absence of substrate; the measurements were made in the presence of $10^{-4} \mathrm{M}$ strophanthidin. Active potassium influx $\left({ }^{1} \mathrm{M}_{\mathrm{K}}{ }^{\mathrm{P}}\right)$ was taken as the difference: ${ }^{1} \mathbf{M}_{\mathbf{K}}{ }^{\mathbf{T}}-{ }^{1} \mathrm{M}_{\mathrm{K}}{ }^{\mathrm{L}}$. The conditions of incubation during depletion and repletion and the rationale for defining the active potassium influx in this manner have been described (1).

Each experiment reported here is representative of three similar experiments in all of which the results were comparable.

Theoretical. The relation between the active potassium influx in the human red blood cell and the extracellular potassium concentration may be described by equations derived from a model of the form:

$$
\begin{aligned}
X+\mathrm{K}_{0} \underset{\mathrm{k}_{-1}}{\stackrel{\mathrm{k}_{1}}{\rightleftharpoons}} X \mathrm{~K} \\
X \mathrm{~K}+\mathrm{K}_{0} \underset{\mathrm{k}_{2}}{\stackrel{\mathrm{k}_{2}}{\rightleftharpoons}} X 2 \mathrm{~K} \\
X 2 \mathrm{~K} \stackrel{\mathrm{k}_{3}}{\longrightarrow} X \mathrm{~K}+\mathrm{K}_{\mathrm{i}}
\end{aligned}
$$

where $X$ is a component (or interrelated components) of the transport system, present in limited quantities, and requiring the presence of two potassium ions before functioning; $\mathrm{K}_{0}$ is extracellular potassium; and $\mathrm{K}_{1}$ is intra- cellular potassium. The active potassium influx, ${ }^{1} \mathrm{M}_{\mathrm{K}}{ }^{\mathrm{P}}=$ $\mathrm{k}_{3} X 2 \mathrm{~K}$; assuming that $\mathrm{k}_{3}$ is so much less than the other rate constants that reactions 1 and 2 may be considered at equilibrium, one may obtain:

$$
{ }^{\mathrm{i}} \mathrm{M}_{\mathrm{K}} \mathrm{P}=\frac{\mathrm{a}}{1+\frac{\mathrm{b}}{\left[\mathrm{K}_{0}\right]}+\frac{\mathrm{c}}{\left[\mathrm{K}_{0}\right]^{2}}}
$$

or:

$$
\frac{1}{{ }^{\mathrm{M}} \mathrm{M}_{\mathrm{K}}^{\mathrm{P}}}=\frac{1}{\mathrm{a}}+\frac{\mathrm{b}}{\mathrm{a}} \frac{1}{\left[\mathrm{~K}_{0}\right]}+\frac{\mathrm{c}}{\mathrm{a}} \frac{1}{\left[\mathrm{~K}_{0}\right]^{2}}
$$

where $a, b$, and $c$ are constants and $\left[K_{0}\right]$ is the extracellular potassium concentration.

The behavior which can be predicted for such a system in the presence of a substance that competes with potassium for the potassium-sensitive sites will depend on whether or not the substance will produce the same alteration in the system as does potassium. If there is a substance $I$, different from potassium, which can replace potassium at both potassium-sensitive sites and produce the same alteration in the transport system as does potassium, and if $\left[\mathrm{K}_{0}\right]$ is held constant, $\left[I_{0}\right]$ (the extracellular concentration of $I$ ) varied, and the active potassium influx $\left({ }^{1} \mathrm{M}_{\mathbf{K}}{ }^{\mathrm{P}}\right)$ measured, the relation between ${ }^{1} \mathrm{M}_{\mathbf{K}}{ }^{\mathrm{P}}$ and $\left[I_{0}\right]$ will be described by:

$$
\frac{1}{{ }^{\mathrm{M}_{\mathrm{K}} \mathrm{P}}}=\mathrm{k}_{1}+\mathrm{k}_{2}\left[I_{0}\right]+\frac{1}{\mathrm{k}_{3}+\mathrm{k}_{4}\left[I_{0}\right]},
$$

where $k_{1}, k_{2}, k_{3}$, and $k_{4}$ are constants. Such a relation has been found when active potassium influx is measured in the presence of rubidium, cesium, or lithium (1).

If the competing substance does not produce the same alteration in the system as does potassium, three possibilities exist depending on whether the substance competes with potassium only at the first site (reaction 1), only at the second site (reaction 2), or at both sites (reactions 1 and 2). If the competing substance competes with potassium only at the first site (i.e., competes with potassium in the formation of $X \mathrm{~K}$, but not in the formation of $X 2 \mathrm{~K}$ ), then the relation between the active potassium influx and the extracellular potassium concentration in the presence of the inhibitor $I$ will be:

$$
\mathrm{i}_{\mathrm{K}} \mathrm{P}=\frac{\mathrm{a}}{1+\frac{\mathrm{b}}{\left[\mathrm{K}_{0}\right]}+\frac{\mathrm{c}}{\left[\mathrm{K}_{0}\right]^{2}}\left(1+\frac{\left[I_{0}\right]}{\mathrm{d}}\right)}
$$

where $a, b, c$, and $d$ are constants. If the competing substance competes with potassium only at the second site (i.e., competes with potassium in the formation of $X 2 \mathrm{~K}$, but not in the formation of $X \mathrm{~K}$ ), then the relation will be:

$$
{ }^{i} \mathrm{M}_{\mathrm{K}} \mathrm{P}=\frac{\mathrm{a}}{1+\frac{\mathrm{b}}{\left[\mathrm{K}_{0}\right]}\left(1+\frac{\left[I_{0}\right]}{\mathrm{d}}\right)+\frac{\mathrm{c}}{\left[\mathrm{K}_{0}\right]^{2}}},
$$

where a, b, c, and d are constants. Finally, if the competing substance competes with potassium at both sites 
(i.e., competes with potassium in the formation of both $X \mathrm{~K}$ and $X 2 \mathrm{~K}$ ), then the relation will be :

$$
{ }^{i} \mathrm{M}_{\mathrm{K}} \mathrm{P}=\frac{\mathrm{a}}{1+\frac{\mathrm{b}}{\left[\mathrm{K}_{0}\right]}\left(1+\frac{\left[I_{0}\right]}{\mathrm{d}}\right)+\frac{\mathrm{c}}{\left[\mathrm{K}_{0}\right]^{2}}\left(1+\frac{\left[I_{0}\right]}{\mathrm{e}}\right)},
$$

where a, b, c, d, and e are constants. By comparing these equations with equation 4 , it can be seen that if $I$ competes only at the first site, the coefficient of the term in $1 /\left[\mathrm{K}_{0}\right]^{2}$ will be increased; if $I$ competes only at the second site, the coefficient of the term in $1 /\left[\mathrm{K}_{0}\right]$ will be increased; and if $I$ competes at both sites, the coefficients of both $1 /\left[\mathrm{K}_{0}\right]$ and $1 /\left[\mathrm{K}_{0}\right]^{2}$ will be increased.

If the active potassium influx is measured in the presence of a constant extracellular potassium concentration but at varying extracellular concentrations of inhibitor, the relation between the active potassium influx and the extracellular concentration of inhibitor will be the same in all three cases:

or :

$$
{ }^{\mathrm{i}} \mathrm{M}_{\mathbf{K}} \mathbf{P}=\frac{1}{\mathrm{k}_{1}+\mathrm{k}_{2}\left[I_{0}\right]}
$$

$$
\frac{1}{\mathrm{i}_{\mathrm{K}^{\mathrm{P}}}}=\mathrm{k}_{1}+\mathrm{k}_{2}\left[I_{0}\right]
$$

where $k_{1}$ and $k_{2}$ are constants.

\section{Results}

The effect of extracellular sodium on the active potassium influx. In Fig. 1, the reciprocal of the active potassium influx measured in the presence

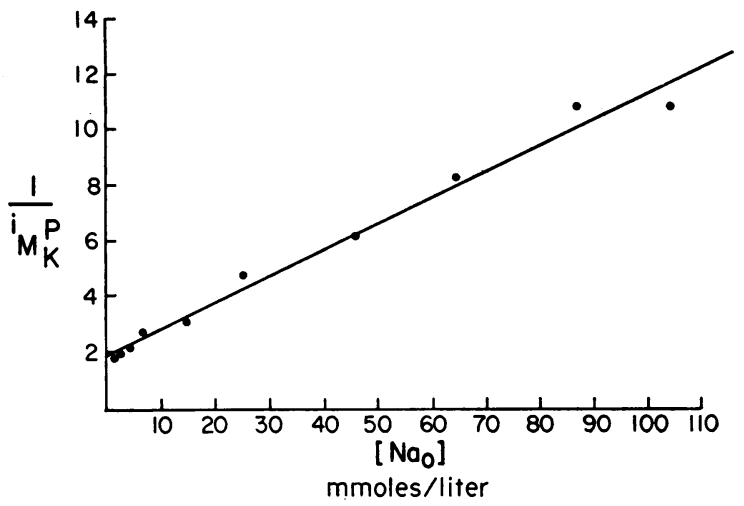

Fig. 1. THE RECIPROCAL OF THE ACTIVE POTASSIUM INFLUX, $1 /{ }^{i} M_{K}{ }^{P}$, LITER RED BLOOD CELLS PER HOUR/ [MMOLES PER LITER], VS. THE EXTRACELLULAR SODIUM CONCENTRATION, [ $\left.\mathrm{Na}_{0}\right]$ 1/[MMOLES PER LITER] AT CONSTANT EXTRACELLULAR POTASSIUM CONCENTRATION. The curve is:

$$
\frac{1}{\mathrm{i}_{\mathrm{K}} \mathrm{P}^{\mathrm{P}}}=1.88+0.095\left[\mathrm{Na}_{0}\right] \text {. }
$$

$r$ (correlation coefficient $)=0.992$. The solutions in which the measurements were made contained (mmoles/liter): glycyl glycine, $77 \rightarrow 40 ; \mathrm{Mg}^{++}, 93 \rightarrow 28 ; \mathrm{Na}^{+}, 0 \rightarrow 108 ; \mathrm{K}^{+}$, $0.14 ; \mathrm{Cl}^{-}, 150 ; \mathrm{PO}_{4}, 1.2 ;$ glucose, 9 ; ethanol, $1 \% \mathrm{v} / \mathrm{v}$. As the concentration of sodium increases, the concentrations of glycyl glycine and of magnesium decrease.

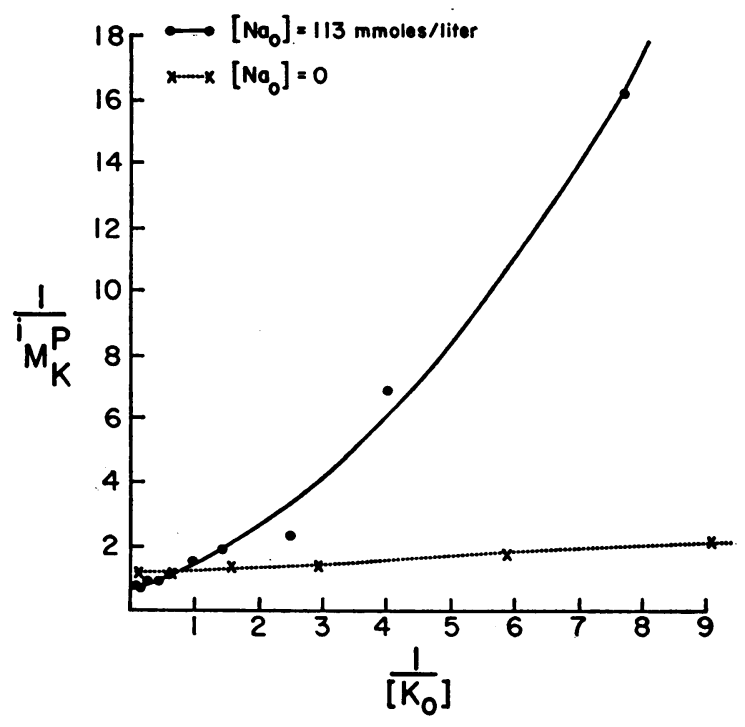

Fig. 2. THE RECIPRoCal OF THE ACtIVE POTASSIUM INFLUX, $1 /{ }^{i} M_{K}{ }^{P}$, LITER RED BLOOD CELLS PER HOUR/ [MMOLES PER LITER], VS. THE RECIPROCAL OF THE EXTRACELLULAR POTASSIUM CONCENTRATION, 1/[K $\left.\mathrm{K}_{0}\right], 1 /$ [MMOLES PER LITER], IN THE PRESENCE AND ABSENCE OF EXTRACELlULAR SODIUM. The curve for the experiment in the presence of sodium is:

$$
\frac{1}{\mathrm{i}_{\mathrm{K}^{\mathrm{P}}}}=0.60+0.62 \frac{1}{\left[\mathrm{~K}_{0}\right]}+0.19 \frac{1}{\left[\mathrm{~K}_{0}\right]^{2}}
$$

$\rho$ (index of curvilinear correlation) $=0.995$. The curve for the experiment in the absence of sodium is:

$$
\frac{1}{\mathrm{i}_{\mathrm{K}} \mathrm{P}^{\mathrm{P}}}=1.09+0.113 \frac{1}{\left[\mathrm{~K}_{0}\right]} \text {. }
$$

$r=0.990$. The solutions used for the measurements in the presence of extracellular sodium contained (mmoles) liter): glycyl glycine, $33 \rightarrow 28 ; \mathrm{Mg}^{++}, 15 \rightarrow 5 ; \mathrm{K}^{+}$, $0.13 \rightarrow 16.7 ; \mathrm{Na}^{+}, 130 ; \mathrm{Cl}^{-}, 145 ; \mathrm{PO}_{4}, 1.2 ;$ glucose, $9 ;$ ethanol, $1 \% \mathrm{v} / \mathrm{v}$. The solutions used for the measurements in the absence of extracellular sodium contained (mmoles/liter): glycyl glycine, $77 \rightarrow 76 ; \mathrm{Mg}^{++}, 88 \rightarrow 85$; $\mathrm{K}^{+}, 0.11 \rightarrow 4.4 ; \mathrm{Cl}^{-}, 145 ; \mathrm{PO}_{4}, 1.2 ;$ glucose, 9 ; ethanol, $1 \% \mathrm{v} / \mathrm{v}$. As the concentration of potassium increases, the concentrations of glycyl glycine and of magnesium decrease.

of a constant extracellular potassium concentration of $0.14 \mathrm{mmole} /$ liter is plotted as a function of the extracellular sodium concentration; the line was fitted to the data by the method of least squares. It can be seen that the data are described by an equation of the form of equation 11, and there is no indication of a deviation from linearity as would be predicted by equation 6 , and as is seen in Fig. 4. It therefore appears that sodium competes with potassium but does not activate the potassium influx. The experiment is complicated by the fact that, as the extracellular sodium concentration increases, the intracellular sodium concentration will increase, and the value of the active 


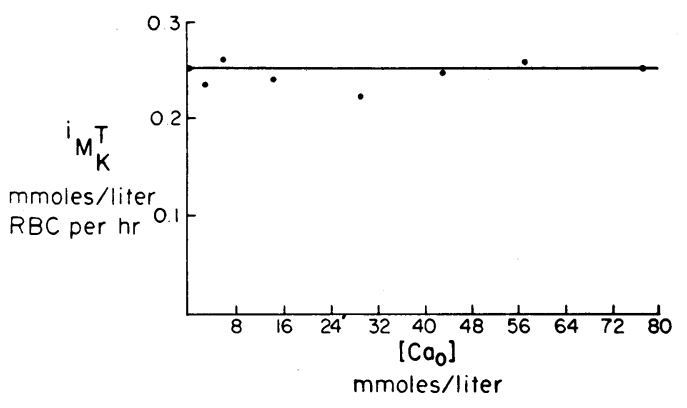

Fig. 3. The total potassium Influx, ${ }^{\mathrm{i}} \mathrm{M}_{\mathrm{K}}{ }^{\mathrm{T}}$, vs. The EXTRACELLULAR CALCIUM CONCENTRATION, [Ca 0 , AT CONSTANT EXTRACELLULAR POTASSIUM CONCENTRATION. The line is ${ }^{i} M_{K}{ }^{T}=0.253$. The solutions in which the measurements were made contained (mmoles/liter): glycyl glycine, $77 ; \mathrm{Mg}^{++}, 92 \rightarrow 15 ; \mathrm{Ca}^{++}, 0 \rightarrow 77 ; \mathrm{K}^{+}$, $0.11 ; \mathrm{Cl}^{-}, 155$; glucose, 9 ; ethanol, $1 \% \mathrm{v} / \mathrm{v}$. As the concentration of calcium increases the concentration of magnesium decreases.

potassium influx measured in the presence of sodium will therefore be higher than it would be if the intracellular sodium concentration could be maintained constant (2). The error which this will cause, however, is in a direction opposite to the observed findings; i.e., if the intracellular sodium concentration remained constant, the slope of the curve in Fig. 1 would be somewhat steeper.

The results of an experiment in which the active potassium influx was measured as a function of varying extracellular potassium concentration in the presence and absence of extracellular sodium are represented in Fig. 2; the reciprocal of the active potassium influx is plotted against the reciprocal of the extracellular potassium concentration, and the curves are fitted by the method of least squares. The data from the experiment in the presence of sodium are well described by a curve of the form of equation 5 , and the data from the experiment in the absence of sodium are described by a similar equation without the term in $1 /\left[K_{0}\right]^{2}$. The means of the values of the constants a, b, and c of equation 5 from three experiments in the presence of sodium were $\mathrm{a}=1.74$ (1.67-1.85), $b=1.24(0.85-1.83)$, and $c=0.30$ $(0.27-0.32)$. The mean values of the constants from three experiments in the absence of sodium were $a=0.87 \quad(0.75-0.91), b=0.096 \quad(0.085-$ $0.102)$, and $c=0$. Since the presence of sodium raises both the coefficient of $1 /\left[\mathrm{K}_{0}\right]$ (from 0.096 to 1.24 ) and the coefficient of $1 /\left[\mathrm{K}_{0}\right]^{2}$ (from 0 to 0.30 ), it can be concluded from equation 9 that sodium competes at both sites, and that the two sites are indistinguishable as far as sodium is concerned. The value of the constant a (which corresponds to the maximum value of the active potassium influx in the presence of sufficient extracellular potassium to saturate the system) is considerably lower in the absence of sodium (0.87) than in its presence (1.74). It is possible that this is due to a decrease in intracellular sodium in the cells incubated in the absence of extracellular sodium, but other mechanisms may also be involved.

The effect of extracellular calcium on the active potassium influx. Fig. 3 represents the results of an experiment in which the total potassium influx was measured in the presence of a constant extracellular potassium concentration of $0.11 \mathrm{mmole} /$ liter and a varying extracellular calcium concentration. It can be seen that calcium does not compete with potassium even when the ratio of the calcium concentration to the potassium concentration is greater than 700 to 1 . The total potassium influx is presented because depleted cells rapidly lose potassium when exposed to high concentrations of calcium, and therefore it is not possible to measure the passive potassium influx or to compute the active potassium influx. Depleted cells which have been repleted by incubation with adenine, inosine, and glucose do not lose potassium in the presence of calcium, and it appears unlikely that the passive potassium influx is much altered under these circumstances. Even if the passive potassium influx were increased five times above normal (a value which would be clearly reflected in a decrease in the cellular potassium concentration), the value of the passive potassium influx would be less than $0.01 \mathrm{mmole} /$ liter of red blood cells per hour, and this would not significantly alter the results presented in Fig. 3. Therefore, the total potassium influx is an adequate reflection of the active potassium influx at the low values of extracellular potassium used here.

The effect of extracellular ammonium concentration on the active potassium influx. In Fig. 4, the results of an experiment in which active potassium influx was measured at a constant extracellular potassium concentration of $0.18 \mathrm{mmole} /$ liter and at varying extracellular ammonium concentrations are plotted; the curve was fitted to the data by trial and error. The results are described 
by an equation of the form of equation 6 , and this behavior is similar to that previously described for rubidium, cesium, and lithium (1). From this it may be concluded that the ammonium ion interacts with both potassium-sensitive sites, and brings about the same alteration in the transport system as does potassium. The behavior of the red blood cell in the presence of ammonium salts is complex in that the cell is freely permeable to $\mathrm{NH}_{3}$ but apparently relatively impermeable to $\mathrm{NH}_{4}^{+}(3,4)$. Thus, one would expect the cells to swell at the higher concentrations of ammonium ion used in this study. There was, however, no hemolysis even at the highest concentration of ammonium chloride used, and the value of the passive potassium influx did not increase. Secondly, since $\mathrm{NH}_{4}{ }^{+}$is in equilibrium with atmospheric $\mathrm{NH}_{3}$, the actual concentration of $\mathrm{NH}_{4}{ }^{+}$in the flasks in which the measurements were made was probably somewhat lower than that reported, although the loss should be small at $\mathrm{pH} 7.4$ and over the short time intervals involved. Since what is measured in this experiment is the influx of potassium in the presence of $\mathrm{NH}_{4}^{+}$, and not the influx of $\mathrm{NH}_{4}{ }^{+}$, it

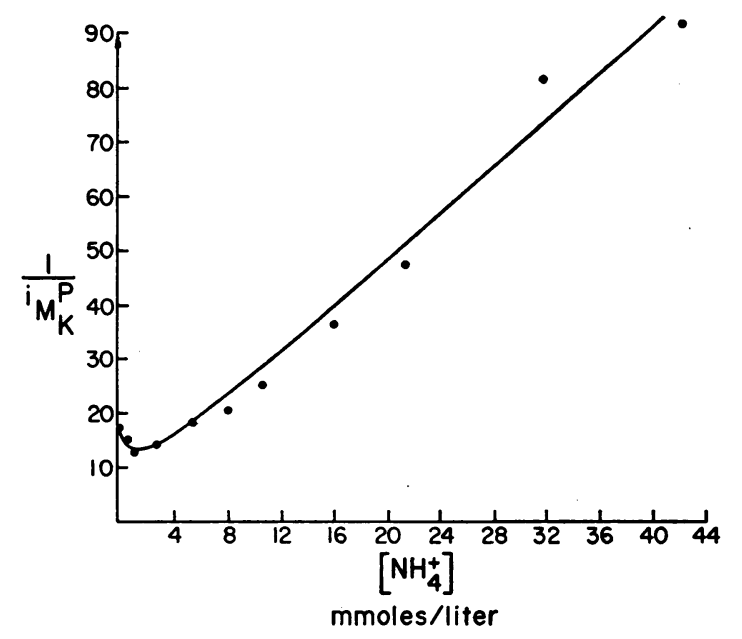

Fig. 4. THE RECIPROCAL OF THE ACTIVE POTASSIUM INFLUX, $1 /{ }^{\mathrm{i}} \mathrm{M}_{\mathrm{K}}{ }^{\mathrm{P}}$, LITER RED BLOOD CELLS PER HOUR/ [MMOLES PER LITER], VS. THE EXTRACELLULAR AMMONIUM CONCENTRATION, $\left[\mathrm{NH}_{4}^{+}\right]$, AT CONSTANT EXTRACELLULAR POTASSIUM CONCENTRATION. The curve is:

$$
\frac{1}{\mathrm{i}_{\mathrm{K}}^{\mathrm{P}}}=4.5+2.14\left[\mathrm{NH}_{4}{ }^{+}\right]+\frac{1}{0.08+0.063\left[\mathrm{NH}_{4}{ }^{+}\right]} \text {. }
$$

$\rho=0.988$. The solutions in which the measurements were made contained (mmoles/liter): glycyl glycine, $46 \rightarrow 31$; $\mathrm{Mg}^{++}, 37 \rightarrow 12 ; \mathrm{NH}_{4}^{+}, 0 \rightarrow 43 ; \mathrm{Na}^{+}, 92 ; \mathrm{K}^{+}, 0.18 ; \mathrm{Cl}^{-}$, $145 ; \mathrm{PO}_{4}, 1.2$; glucose, 9 ; ethanol, $1 \% \mathrm{v} / \mathrm{v}$. As the concentration of ammonium increases, the concentrations of glycyl glycine and of magnesium decrease.

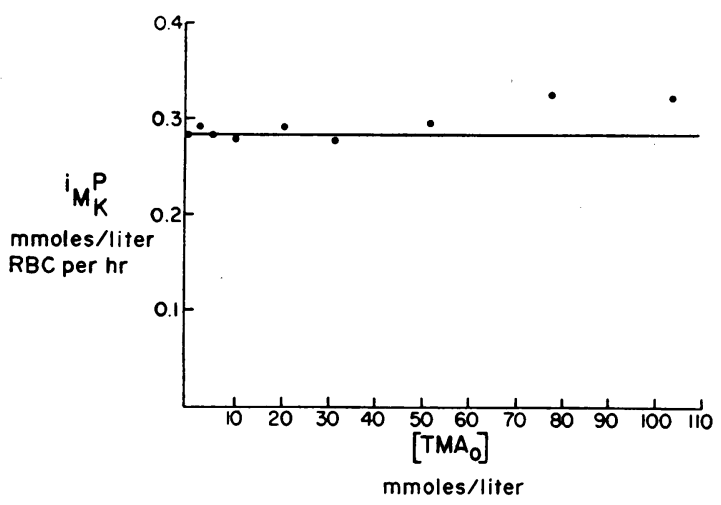

Fig. 5. The active potassium INFLUX, ${ }^{i} M_{K}{ }^{P}$, vs. The EXTRACELLULAR CONCENTRATION OF TETRAMETHYLAMMONIUM, [TMA $A_{0}$, AT CONSTANT EXTRACELLULAR POTASSIUM CONCENTRATION. The line is i $\mathrm{M}_{\mathrm{K}}^{\mathrm{P}}=0.284$. The solutions in which the measurements were made contained (mmoles/liter): glycyl glycine, $64 \rightarrow 28 ; \mathbf{M g}^{++}$ $69 \rightarrow 5 ;$ TMA $^{+}, 0 \rightarrow 102 ; \mathrm{Na}^{+}, 38 ; \mathrm{K}^{+}, 0.24 ; \mathrm{Cl}^{-}, 147$ $\mathrm{PO}_{4}, 1.2$; glucose, 9 ; ethanol, $1 \% \mathrm{v} / \mathrm{v}$. As the concentration of tetramethylammonium increases, the concentrations of glycyl glycine and of magnesium decrease.

is unlikely that either of these complications would alter the form of the response, although the values of the constants involved may be somewhat uncertain.

The effect of extracellular tetramethylammonium on the active potassium influx. The results of an experiment in which the active potassium influx was measured in the presence of a constant extracellular potassium concentration of 0.24 mmole/liter and a variable extracellular concentration of tetramethylammonium ion are depicted in Fig. 5. There is no marked influence of tetramethylammonium on the active potassium influx, although the potassium influx does appear somewhat higher at the highest concentrations of tetramethylammonium used. Although this was a constant finding, the magnitude of the increase was small and its significance is not clear. It is possible that tetramethylammonium behaves like $\mathrm{NH}_{4}{ }^{+}$but to a much smaller extent. The solution which replaced tetramethylammonium chloride was composed of $80 \%$ isosmotic $\mathrm{MgCl}_{2}$ solution and $20 \%$ isosmotic glycyl glycine- $\mathrm{MgCO}_{3}$ solution. The behavior of the active potassium influx in the presence of tetramethylammonium ions appears to be about equivalent to its behavior in the presence of magnesium ions.

To be certain that the influence of sodium on the active potassium influx reported above can be 


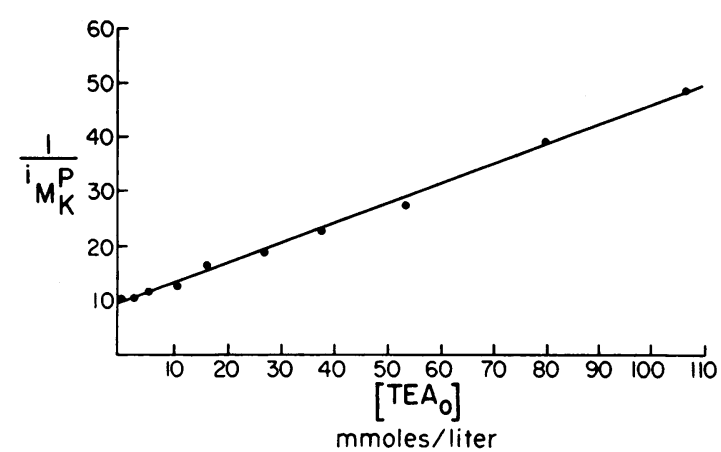

FIG. 6. THE RECIPROCAL OF THE ACTIVE POTASSIUM INFLUX, $1 /{ }^{\text {i }} \mathrm{M}_{\mathrm{K}}{ }^{\mathrm{P}}$, LITER RED BLOOD CELLS PER HOUR/ [MMOLES PER LITER], VS. THE EXTRACELLULAR CONCENTRATION OF TETRAETHYLAMMONIUM, (TEA 0 , AT CONSTANT EXTRACELLULAR POTASSIUM CONCENTRATION. The line is:

$$
\frac{1}{\mathrm{i}_{\mathrm{K}}^{\mathrm{P}}}=9.51+0.361\left[\mathrm{TEA}_{0}\right] \text {. }
$$

$r=0.998$. The solutions in which the measurements were made contained (mmoles/liter): glycyl glycine, $64 \rightarrow 27 ; \mathrm{Mg}^{++}, 69 \rightarrow 5 ;$ TEA $^{+}, 0 \rightarrow 107 ; \mathrm{Na}^{+}, 38 ; \mathrm{K}^{+}$, $0.15 ; \mathrm{Cl}^{-}, 147 ; \mathrm{PO}_{4}, 1.2$; glucose, 9 ; ethanol, $1 \% \mathrm{v} / \mathrm{v}$. As the concentration of tetraethylammonium increases, the concentrations of glycyl glycine and of magnesium decrease. Note that the scale on the ordinate is compressed as compared to Fig. 1, and that the slope of this line is greater than that of Fig. 1.

attributed to increasing sodium concentration rather than to decreasing magnesium concentration, we performed experiments in which the total potassium influx was measured in the presence or absence of sodium, with tetramethylammonium replacing sodium. The measurements were made at an extracellular potassium concentration of $0.20 \mathrm{mmole} / \mathrm{liter}$. The mean of three determinations in the presence of tetramethylammonium was $0.73(0.68-0.75) \mathrm{mmole} / \mathrm{liter}$ of red blood cells per hour, and the mean of three determinations in the presence of sodium was $0.27(0.23-0.32)$ mmole/liter of red cells per hour. The diminished active potassium influx in the presence of sodium is apparent when the ion replacing sodium is tetramethylammonium as well as when it is magnesium.

The effect of extracellular tetraethylammonium on the active potassium influx. Fig. 6 represents the results of an experiment in which the active potassium influx was measured in the presence of a constant extracellular potassium concentration of $0.15 \mathrm{mmole} / \mathrm{liter}$ and varying extracellular concentrations of tetraethylammonium. The reciprocal of the active potassium influx is plotted against the extracellular tetraethylammonium con- centration; the line was fitted to the data by the method of least squares. The results are described by an equation of the form of equation 11 . The behavior of the active potassium influx in the presence of tetraethylammonium is similar to its behavior in the presence of sodium, and the potency of tetraethylammonium as an inhibitor of the active potassium influx is greater than that of sodium, as reflected by the slopes of the lines. The

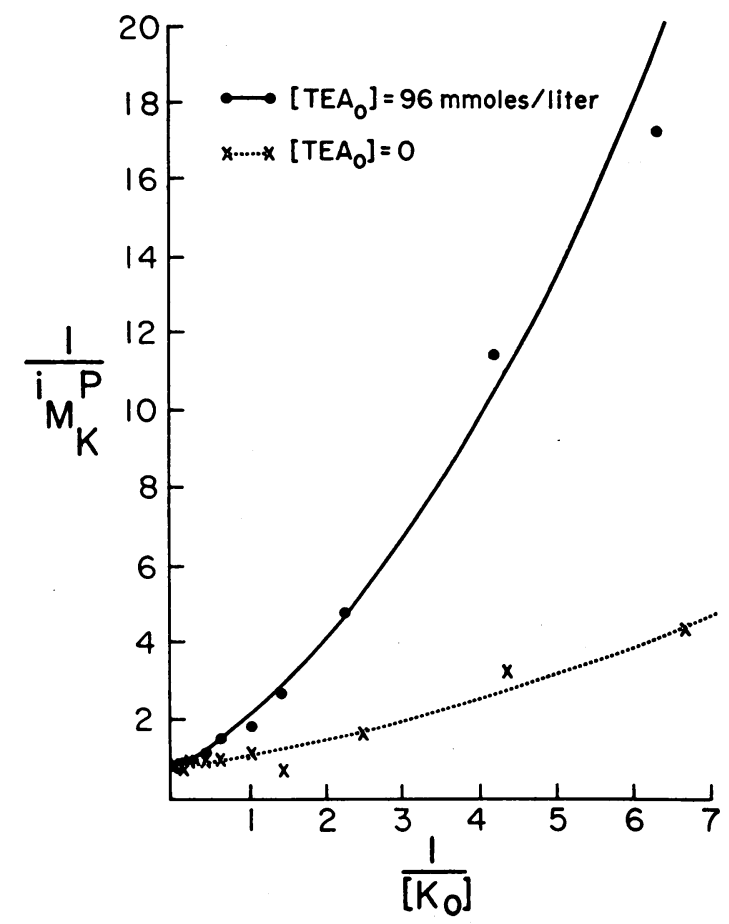

Fig. 7. THE RECIPRocal OF THE aCtive POTASSIUM INFLUX, $1 /{ }^{\mathrm{i}} \mathbf{M}_{\mathrm{K}}{ }^{\mathrm{P}}$, LITER RED BLOOD CELLS PER HOUR/ [MMOLES PER LITER], VS. THE RECIPROCAL OF THE EXTRACELLULAR POTASSIUM CONCENTRATION, $1 /\left[\mathrm{K}_{0}\right], 1 /$ [MMOLES PER LITER], IN THE PRESENCE OF EXTRACELLULAR TETRAETHYLAMMONIUM. The curve for the experiment in the presence of extracellular tetraethylammonium is:

$$
\frac{1}{\mathrm{i}_{\mathrm{K}} \mathrm{M}^{\mathrm{P}}}=0.65+1.10 \frac{1}{\left[\mathrm{~K}_{0}\right]}+0.30 \frac{1}{\left[\mathrm{~K}_{0}\right]^{2}} \text {. }
$$

$\rho=0.992$. The curve for the experiment in the absence of tetraethylammonium is:

$$
\frac{1}{{ }^{i} \mathrm{M}_{\mathrm{K}} \mathrm{P}}=0.72+0.30 \frac{1}{\left[\mathrm{~K}_{0}\right]}+0.04 \frac{1}{\left[\mathrm{~K}_{0}\right]^{2}} \text {. }
$$

$\rho=0.968$. The solutions used for the measurements in the presence of tetraethylammonium contained (mmoles) liter): glycyl glycine, $66 \rightarrow 60 ; \mathrm{Mg}^{++}, 15 \rightarrow 5 ; \mathrm{K}^{+}$, $0.15 \rightarrow 16.2 ; \mathrm{TEA}^{+}, 96 ; \mathrm{Na}^{+}, 33 ; \mathrm{Cl}^{-}, 143 ; \mathrm{PO}_{4}, 1.2$; glucose, 9 ; ethanol, $1 \% \mathrm{v} / \mathrm{v}$. 'The solutions used for the measurements in the absence of tetraethylammonium contained (mmoles/liter) : glycyl glycine, $33 \rightarrow 27 ; \mathrm{Mg}^{++}$, $73 \rightarrow 63 ; \mathrm{K}^{+}, 0.12 \rightarrow 16.2 ; \mathrm{Na}^{+}, 33 ; \mathrm{Cl}^{-}, 148 ; \mathrm{PO}_{4}, 1.2$; glucose, 9 ; ethanol, $1 \% \mathrm{v} / \mathrm{v}$. As the concentration of potassium increases, the concentrations of glycyl glycine and of magnesium decrease. 
mean of the values of the slope from three experiments in which the concentration of tetraethylammonium was the variable was $0.33(0.28-0.36)$, while the mean of the values from three experiments in which sodium was the variable was 0.081 $(0.067-0.095)$; the measurements were in all cases made at about the same extracellular potassium concentration, so that the results are comparable. There was no discernible effect of tetraethylammonium on the passive potassium influx.

Fig. 7 represents the results of an experiment in which the active potassium influx was measured in the presence of varying extracellular potassium concentrations in the presence and absence of 96 mM tetraethylammonium ion; tetraethylammonium was replaced by a solution containing $80 \%$ isosmotic $\mathrm{MgCl}_{2}$ solution and $20 \%$ isosmotic glycyl glycine- $\mathrm{MgCO}_{3}$ solution. The reciprocal of the active potassium influx is plotted against the reciprocal of the extracellular potassium concentration and the curves were fitted to the data by the method of least squares. It can be seen that the coefficients of both $1 /\left[\mathrm{K}_{0}\right]$ and $1 /\left[\mathrm{K}_{0}\right]^{2}$ are increased in the presence of tetraethylammonium ion. In accordance with equation 9, it appears that tetraethylammonium competes with potassium at both potassium-sensitive sites.

\section{Discussion}

Similar findings for the interaction of some of these ions with various aspects of the red cell cation transport system have previously been reported by others. Post, Merritt, Kinsolving, and Albright (5) have demonstrated that external sodium inhibits the active potassium influx in human red blood cells and that the inhibition appears competitive. Whittam and Ager (6) have similarly demonstrated that, in reconstituted human red blood cell ghosts, external sodium competitively inhibits the potassium stimulation of ATP hydrolysis. Rummel, Seifen, and Baldauf (7) found no influence of external calcium at concentrations up to 4 mmoles/liter on active potassium influx. Ammonium has been shown by Post and Jolly (8) to inhibit potassium influx competitively in the human red blood cell and to be capable of replacing potassium in the stimulation of active sodium outflux. Tetramethylammonium in the extracellular solution was found by Whittam and Ager (6) to have no effect on the potassium-stimulated ATPase activity of reconstituted red cell ghosts.

The data presented here and previously (1) have been interpreted in terms of a model with the following characteristics: potassium is simultaneously required at two sites in the active transport system before active potassium influx occurs; rubidium, cesium, lithium, and ammonium interact with the potassium-sensitive sites and stimulate the active potassium influx when one of these ions and potassium are both present at low concentrations, but competitively inhibit active potassium influx when they are present at higher concentrations; sodium and tetraethylammonium competitively inhibit the active potassium influx at all concentrations. It was not possible to distinguish between the potassium-sensitive sites from the behavior of the system in the presence of the ions used; this does not, of course, deny that experiments might be devised which would uncover differences in the behavior of the sites.

The effect of sodium and of tetraethylammonium may be interpreted differently. It is possible that these ions do not interact with the potassium-sensitive sites, but react with some other site in the transport system and thereby decrease the sensitivity of the potassium-sensitive sites for potassium. It is not possible to distinguish between the two mechanisms on the basis of the evidence presented. However, if it is proposed that sodium does not interact with the potassium-sensitive sites directly, there remains the difficulty of explaining why sodium, whose physical characteristics are intermediate between those of lithium and potassium, behaves in a manner completely different from that of the other two ions.

Within the framework of the formulation proposed, it is possible to make some inferences about the affinity of the potassium-sensitive sites for univalent cations. The slope of the straight portion of the curve in Fig. 4, i.e., the coefficient of the term in $\left[\mathrm{NH}_{4}^{+}\right]$, can be taken as a measure of the affinity of the potassium-sensitive sites for $\mathrm{NH}_{4}{ }^{+}$compared to their affinity for potassium. Similar values can be obtained from previously reported studies (1) for the relative affinity of the system for rubidium, cesium, and lithium compared to its affinity for potassium. An estimate 
of the relative affinity for sodium and tetraethylammonium can be made from the slope of the lines in Figs. 1 and 6 . Since all measurements were made at about the same extracellular potassium concentration, the results are comparable. Finally, an estimate of the affinity of the system for potassium can be made by calculating the efficacy of potassium as an inhibitor of the active potassium influx, i.e., the rate at which the "rate constant" for active potassium influx decreases with increasing extracellular potassium. From these calculations, the ions can be arranged in the following order of decreasing affinity for the potassium-sensitive sites: $\mathrm{Rb}>\mathrm{K}>\mathrm{NH}_{4}>\mathrm{Cs}>$ $\mathrm{TEA}>\mathrm{Na}>\mathrm{Li}$. The sequence for the alkali metal cations, $\mathrm{Rb}>\mathrm{K}>\mathrm{Cs}>\mathrm{Na}>\mathrm{Li}$, does not coincide with a Hofmeister series ranking the ions in the order of their estimated hydrated ionic radii, nor with a ranking in the order of their crystal ionic radii. Eisenman (9) has pointed out that the anionic field strength at the site at which the cation will interact, together with the cationic hydration energy, will determine the order of selectivity of the site for the cations. From this he has developed a series of sequences of the univalent cations corresponding to different anionic field strengths at the receptor. The sequence found here corresponds to Eisenman's sequence III.

Although the apparent affinity of the potassiumsensitive sites of this system for the alkali metal cations may be accounted for by the physical characteristics of the cations, the fact remains that rubidium, cesium (10-12), potassium, and lithium (2) are actively transported inward, but sodium, which is intermediate in its physical characteristics between potassium and lithium (13), is not (2). Since the apparent affinity of the potassium-sensitive sites for the cations does not seem to explain this aberration, it may be that some alteration induced in the transport system by the cation subsequent to its binding to the potassium-sensitive sites is involved, i.e., rubidium, potassium, cesium, and lithium after being bound alter the system in such a way that they are actively transported inward, but sodium does not produce this alteration.

The effect of tetraethylammonium is somewhat difficult to explain. The tetraethylammonium ion is apparently unhydrated in solution and its ionic radius is $4.00 \mathrm{~A}$, which is larger than estimates of the hydrated ionic radius of the other ions (13). It is possible that tetraethylammonium acts on some site other than the potassium-sensitive sites as discussed above. However, it is also conceivable that, if the two potassium-sensitive sites are adjacent, one tetraethylammonium ion might be capable of simultaneously fitting both sites and thereby restricting the access of potassium to them. This is not the only system in which tetraethylammonium ions inhibit potassium movements; similar effects have been observed in neural preparations $(14,15)$.

Substituted ammonium ions have frequently been used to replace sodium and potassium in physiological investigations. Askari (16) has pointed out that choline, tetramethylammonium, and tetraethylammonium appear to interact with the red cell membrane so that their entry into the cell is facilitated, and has suggested that assumptions that the ions are inert may be erroneous. In the potassium transport system of the human red blood cell, this certainly seems to be true for tetraethylammonium.

\section{Acknowledgments}

I wish to thank Dr. Louis G. Welt for his advice, support, and encouragement during the course of these investigations.

\section{References}

1. Sachs, J. R., and L. G. Welt. 1967. The concentration dependence of active potassium transport in the human red blood cell. J. Clin. Invest. 46: 65.

2. McConaghey, P. D., and M. Maizels. 1962. Cation exchanges of lactose treated human red cells. J. Physiol. (London). 162: 485.

3. Jacobs, M. H., and A. K. Parpart. 1938. Osmotic properties of the erythrocyte. X. On the permeability of the erythrocyte to ammonia and the ammonium ion. J. Cellular Comp. Physiol. 11: 175.

4. Jacobs, M. H., and D. R. Stewart. 1942. The role of carbonic anhydrase in certain ionic exchanges involving the erythrocyte. J. Gen. Physiol. 25: 539.

5. Post, R. L., C. R. Merritt, C. R. Kinsolving, and C. D. Albright. 1960. Membrane adenosine triphosphatase as a participant in the active transport of sodium and potassium in the human erythrocyte. J. Biol. Chem. 235: 1796.

6. Whittam, R., and M. E. Ager. 1964. Vectorial aspects of adenosine-triphosphatase activity in erythrocyte membranes. Biochem. J. 93: 337. 
7. Rummel, W., E. Seifen, and J. Baldauf. 1963. Influence of calcium and ouabain upon the potassium influx in human erythrocytes. Biochem. Pharmacol. 12 : 557.

8. Post, R. L., and P. C. Jolly. 1957. The linkage of sodium, potassium, and ammonium active transport across the human erythrocyte membrane. Biochim. Biophys. Acta. 25 : 118.

9. Eisenman, G. 1960. On the elementary atomic origin of equilibrium ionic specificity. In Symposium on Membrane Transport and Metabolism. A. Kleinzeller and A. Kotyk, editors. Academic Press Inc., London and New York. 163.

10. Love, W. D., and G. E. Burch. 1953. A comparison of potassium ${ }^{42}$, rubidium ${ }^{86}$, and cesium $^{184}$ as tracers of potassium in the study of cation metabolism of human erythrocytes in vitro. J. Lab. Clin. Med. $41: 351$.
11. Kahn, J. B. 1962. The entry of rubidium into human erythrocytes. J. Pharmacol. Exptl. Therap. 136 : 197.

12. Solomon, A. K. 1952. The permeability of the human erythrocyte to sodium and potassium. J. Gen. Physiol. $36: 57$.

13. Nightingale, E. R. 1959. Phenomonological theory of ion solvation. Effective radii of hydrated ions. J. Phys. Chem. 63 : 1381.

14. Armstrong, C. M., and L. Binstock. 1965. Anomalous rectification in the squid giant axon injected with tetraethylammonium chloride. J. Gen. Physiol. $48: 859$.

15. Nakajima, S. 1966. Analysis of $\mathrm{K}$ inactivation and TEA action in the supramedullary cells of puffer. J. Gen. Physiol. 49 : 629.

16. Askari, A. 1966. Uptake of some quaternary ammonium ions by human erythrocytes. J. Gen. Physiol. 49 : 1147. 